\title{
Investigating the efficacy and safety of mineral smectite granules on wound healing
}

\author{
JIANKUN WANG ${ }^{*}$, MIN WANG ${ }^{*}$, LILI ZHAO, LI LIU, XIANG WANG and ZHINING FAN \\ Digestive Endoscopy Department and General Surgery Department, The First Affiliated Hospital with \\ Nanjing Medical University and Jiangsu Province Hospital, Nanjing, Jiangsu 210029, P.R. China
}

Received August 3, 2019; Accepted September 8, 2020

DOI: 10.3892/etm.2020.9591

\begin{abstract}
Mineral smectite granules have traditionally been used for diarrhea and gastrointestinal bleeding; however, the wound healing ability of mineral smectite granules has not been investigated in detail. Therefore, the present study explored the efficacy and safety of mineral smectite granules on wound healing. An excision wound rat model was established. The experimental group was treated with smectite granules, the positive control group was treated with starch and the blank control group was left untreated. Wound closure rates, wound healing times and histopathological analysis were compared among the three groups. The mechanism underlying the effects of mineral smectite granules on wound healing was assessed by performing picrosirius red staining and immunohistochemical staining and measuring hydroxyproline content. Based on wound closure rates, wound healing times and histopathological analysis, the results indicated that rats treated with smectite granules displayed increased wound healing efficacy compared with the other two groups. Investigation of the underlying mechanism suggested that mineral smectite granules could promote wound healing by inducing collagen fiber synthesis and increasing the number of neovessels. The present study indicated the efficacy and safety of mineral smectite granules on wound healing and provided a theoretical basis for its application in a clinical setting.
\end{abstract}

\section{Introduction}

Wound healing is a complex natural body process involving structural reconstruction and functional recovery (1), which is a

Correspondence to: Professor Zhining Fan, Digestive Endoscopy Department and General Surgery Department, The First Affiliated Hospital with Nanjing Medical University and Jiangsu Province Hospital, 300 Guangzhou Road, Nanjing, Jiangsu 210029, P.R. China E-mail: fan_Zhining@163.com

\section{${ }^{*}$ Contributed equally}

Key words: mineral smectite granules, collagen fiber, hydroxyproline, angiogenesis, wound healing key research focus in the surgical field. Wound healing research involves investigation at the cellular, molecular and gene level. The healing process is conducted by a combination of cytokines, inflammatory cells and repair cells (2), and consists of three phases: Inflammatory response, granulation tissue formation, re-epithelialization and tissue remodeling, which form an ordered metabolic process (3). Although it was reported that several drugs, including fibroblast growth factor, could effectively promote wound healing, some limitations restrict their application, such as high cost, complex production or poor efficacy (4-6); hence, further research is required to identify a more appropriate drug.

Smectite is a common clinical drug that has a strong covering ability in the gastrointestinal mucosa and can activate coagulation factors $(7,8)$. Due to its pharmacological properties, smectite has been used for diarrhea (9) was also reported to display promising results for the treatment of hemorrhages $(10,11)$. The aforementioned effects of smectite have been indicated in previous research, which also indicated that mineral smectite granules may promote wound healing (12). As hemostasis is a part of wound healing, accelerating hemostasis may be helpful for wound healing (13); therefore, it was hypothesized that smectite could accelerate stages of wound healing process.

To the best of our knowledge, few studies have evaluated the application of mineral smectite granules for wound healing. Therefore, a cutaneous wound rat model was established to assess wound healing responses. The present study aimed to explore the efficacy and safety of mineral smectite granules in a cutaneous wound rat model.

\section{Materials and methods}

Animal preparation. A total of 48 Sprague-Dawley rats (male; weight, 320-350 g; age, 8 weeks) were obtained from the Animal Center of Nanjing Medical University (Nanjing, China). The rats were maintained in the animal experiment center of Nanjing Medical University. Each rat was housed in a separate cage at $22 \pm 2^{\circ} \mathrm{C}$ with $50 \%$ humidity and 12 -h light/dark cycles. The animals had free access to food and water. The present study was approved by the Animal Ethical and Welfare Committee of Nanjing Medical University, China (IACUC approval no. 1601136). The animal experiments were conducted according to the relevant guidelines and regulations (14). 
Wound model and topical management. A total of 12 rats were grouped as the normal skin group to provide normal skin tissues. The other 36 rats were anesthetized with intraperitoneal injection of $40 \mathrm{mg} / \mathrm{kg}$ pentobarbital sodium. The dorsal fur was shaved using an electrical clipper and the skin was disinfected with iodine. A full thickness wound area $(2 \times 2 \mathrm{~cm})$ was created in the dorsal region using a scalpel. Subsequently, the rats were randomly divided into three groups $(n=12$ per group): i) The smectite group was treated topically with $0.5 \mathrm{mg} / \mathrm{mm}^{2}$ mineral smectite granules (cat. no. 151207; Shandong Xianhe Pharmaceutical Co., Ltd.). Prior to experiments, a simple pretest to study different concentrations $(0.1,0.5$ and $1.0 \mathrm{mg} / \mathrm{mm}^{2}$ ) of mineral smectite granules for wound healing was performed, and the results showed that the time for complete wound closure was shortest when the concentration was $0.5 \mathrm{mg} / \mathrm{mm}^{2}$ (Table I); ii) the positive control group was treated topically with $0.5 \mathrm{mg} / \mathrm{mm}^{2}$ starch; and iii) the blank control group was left untreated. The mineral smectite granules and starches were in powder form, which was applied directly to the wound without being ground or dissolved. All wounds were covered with sterilized dressing. The wounding day was considered as day 0 .

Wound healing evaluation. During the wound healing period, the wound boundary was photographed every two days until the wound was completely recovered. Different colors of the wound represented different conditions: Bright red=blood covering the wound; dark red=coagulation of blood in the epidermis and red=granulation tissue and pink, which represented the epithelialization phase. Wound areas were measured using ImageJ software (v1.8.0; National Institutes of Health). The wound was considered to be completely closed when the wound was covered by new epithelial tissue. The wound closure rate was defined as a percentage of reduction of the initial wound size according to the following formula: Wound closure $(\%)=($ original wound size-wound size at a specific day)/original wound size $\times 100$. Wound healing time was recorded when the wound displayed complete epithelialization.

Histological examination. When complete wound healing was observed, rats in the blank control, starch, smectite and normal skin groups were sacrificed with intravenous injection of excess pentobarbital sodium $(200 \mathrm{mg} / \mathrm{kg})$. Death of rats were verified when breath and heartbeat of the animals were not detected for more than $3 \mathrm{~min}$. The healing tissue in the middle of the wound area from the blank control, starch and smectite groups and the normal skin tissue in the dorsal region from the normal skin group were excised for histological evaluation. The tissues were fixed in $10 \%$ buffered formalin solution for $24 \mathrm{~h}$ at $4^{\circ} \mathrm{C}$, embedded in paraffin and cut into $5-\mu \mathrm{m}$ thick sections. Subsequently, the sections were stained with hematoxylin and eosin (H\&E). Stained sections were observed using a CK-40 light microscope (magnification, x200; Olympus Corporation) for histological evaluation, including angiogenesis, inflammatory cell infiltration and fibroblast proliferation (5).

Biochemical analysis of collagen fibers. Collagen fibers, which is alkaline, is a main component of the skin that responds strongly to acid dyes such as picrosirius red (15). Tissue sections (5- $\mu \mathrm{m}$ thick) were stained with celestine blue solution for 5-10 min and with picrosirius red solution for $15-30 \mathrm{~min}$, both at $4^{\circ} \mathrm{C}$. Stained sections were observed using a light microscope (x200) to evaluate collagen fiber distribution. For further evaluation, the content of hydroxyproline, the basic constituent of collagen, was measured. The healing tissue was dried at $60-70^{\circ} \mathrm{C}$ for $24 \mathrm{~h}$ and weighed. Dried tissue was hydrolyzed in $6 \mathrm{~N} \mathrm{HCl}$ at $120^{\circ} \mathrm{C}$ for $18 \mathrm{~h}$ in sealed tubes. The hydrolyzed samples were adjusted to $\mathrm{pH} 7.0$ and subjected to chloramine-T oxidation for $20 \mathrm{~min}$ at $37^{\circ} \mathrm{C}$. The reaction was terminated by addition of $3.15 \mathrm{M}$ perchloric acid and para-dimethylaminobenzaldehyde at $60^{\circ} \mathrm{C}$ to develop a pink color. The absorbance of each sample was measured at a wavelength of $557 \mathrm{~nm}$ using an SMA4000 spectrophotometer (Merinton Instrument, Ltd.) (16). The normal skin tissues, which were obtained from the normal skin group, were also subjected to picrosirius red staining and hydroxyproline content evaluation.

Neovascularization evaluation. Paraffin-embedded tissue sections were maintained in xylene at room temperature. Endogenous peroxidase activity was blocked using hydrogen peroxide. Antigen retrieval was performed using ethylenediaminetetraacetic acid at $95^{\circ} \mathrm{C}$. Then the sections were washed with phosphate buffer saline for 3 times. Subsequently, the sections were incubated with a mouse monoclonal anti-CD31 (1:100; cat. no. WH0005175M1; Sigma-Aldrich; Merck KGaA) primary antibody for $1 \mathrm{~h}$ at $37^{\circ} \mathrm{C}$. Subsequently, the sections were incubated with a biotinylated secondary antibody $(1: 300$; cat. no. B9904; IgG; Sigma-Aldrich; Merck KGaA) for $1 \mathrm{~h}$ at $37^{\circ} \mathrm{C}$. In addition, Streptavidin/HRP reagent (cat. no. DY998; Sigma-Aldrich; Merck KGaA) was added to each section. Immunoreactivity was visualized by placing sections in $0.1 \%$ 3.3'-diaminobenzidine and $0.02 \%$ hydrogen peroxide solution (DAB chromogenic system; cat. no. CTS002; Sigma-Aldrich; Merck KGaA). The sections were counterstained with hematoxylin for $30 \mathrm{sec}$ at room temperature (17). Stained sections were observed using a light microscope (x200) and neovascularization was quantified using ImageJ software (v1.8.0; National Institutes of Health). Neovascularization evaluation of the normal skin sections was also performed.

Statistical analysis. Data are presented as the mean \pm SD. The wound closure rate was calculated as a percentage of the original wound area. Differences among multiple groups were compared by one-way ANOVA or the $\chi^{2}$ test. The post hoc analysis was performed using Tukey's test. Statistical analyses were performed using SPSS software (version 19.0; IBM Corp.). $\mathrm{P}<0.05$ was considered to indicate a statistically significant difference.

\section{Results}

Smectite granules promote wound healing. The entire wound healing process is presented in Fig. 1. From day 4, mineral smectite granules significantly increased the rate of wound closure rate compared with blank control and starch groups (Table II). The mean time for complete wound closure in the smectite group was $14.50 \pm 1.07$ days and the color of the wound was close to normal skin. The mean time of complete wound closure in the starch (21.25 \pm 1.91 days) and blank control 
Table I. Wound healing times of differenct smectite concentrations.

\begin{tabular}{lccccccc}
\hline & \multicolumn{7}{c}{ Wound closure rate $(\%)$, mean \pm SD } \\
\cline { 2 - 8 } Group & 2 days & 4 days & 6 days & 8 days & 10 days & 12 days & 14 days \\
\hline Blank control & 0.00 & 0.00 & $15.51 \pm 2.48$ & $33.23 \pm 3.12$ & $63.31 \pm 3.11$ & $82.50 \pm 2.45$ & $88.72 \pm 1.61$ \\
Starch & 0.00 & $4.74 \pm 0.96^{\mathrm{a}}$ & $21.87 \pm 1.46^{\mathrm{a}}$ & $51.73 \pm 2.61^{\mathrm{a}}$ & $74.76 \pm 2.24^{\mathrm{a}}$ & $88.40 \pm 1.02^{\mathrm{a}}$ & $91.92 \pm 1.50^{\mathrm{a}}$ \\
Smectite & 0.00 & $13.92 \pm 1.83^{\mathrm{a}, \mathrm{b}}$ & $36.01 \pm 2.07^{\mathrm{a}, \mathrm{b}}$ & $71.05 \pm 1.64^{\mathrm{a}, \mathrm{b}}$ & $83.86 \pm 1.04^{\mathrm{a}, \mathrm{b}}$ & $95.33 \pm 1.59^{\mathrm{a}, \mathrm{b}}$ & $98.88 \pm 1.20^{\mathrm{a}, \mathrm{b}}$ \\
\hline
\end{tabular}

${ }^{\text {a }} \mathrm{P}<0.05$ vs. blank control; ${ }^{\text {b }}<0.05$ vs. starch.

A
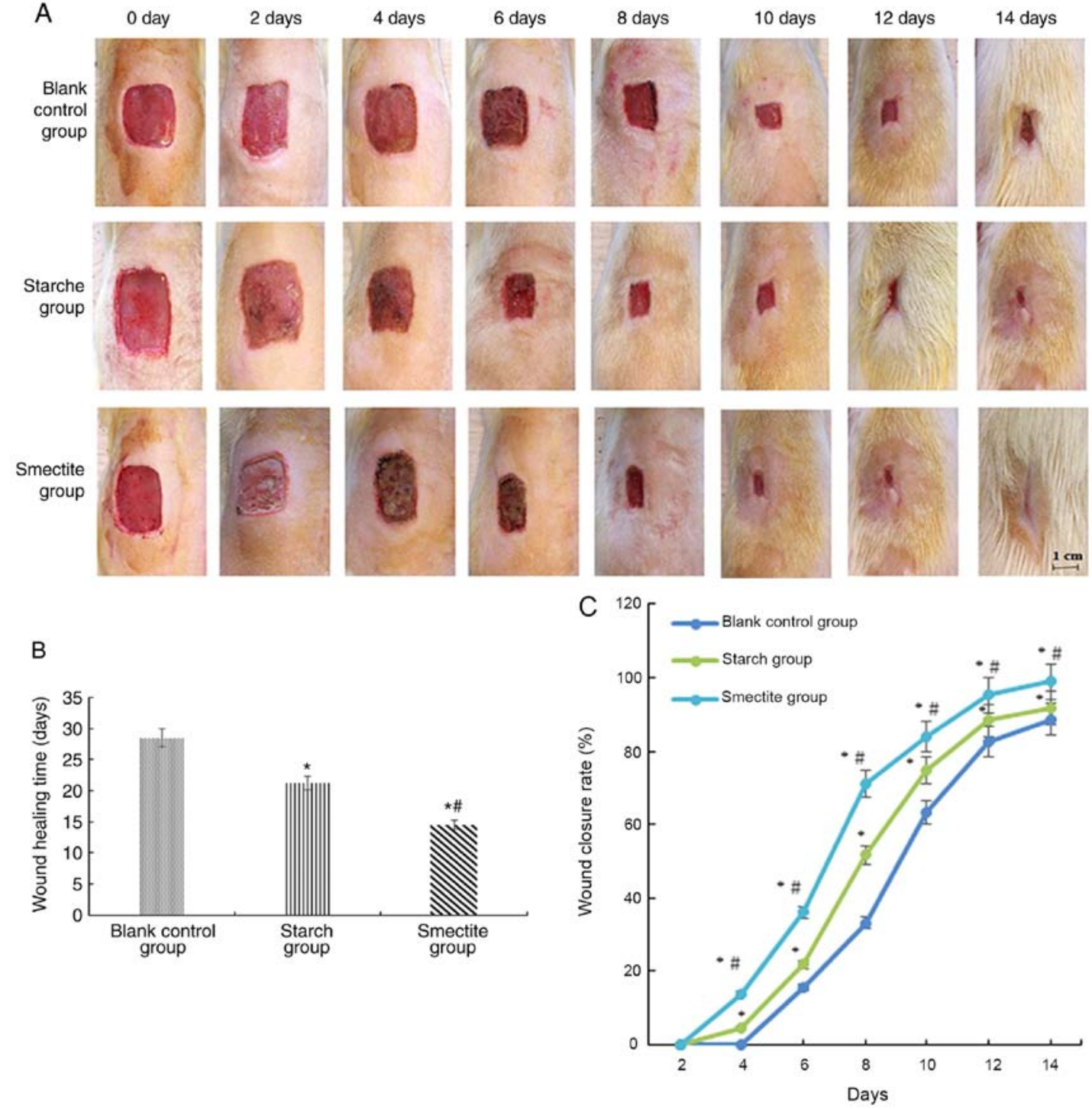

Figure 1. Smectite granules promote wound healing. (A) The wound healing process in each group, Scale bar, $1 \mathrm{~cm}$. (B) Wound healing times in blank control, starch and smectite groups. (C) Wound closure rates in blank control, starch and smectite groups. "P<0.05 vs. blank control. "P<0.05 vs. starch.

(28.50 \pm 1.60 days) groups was significantly longer compared with the smectite group.

Smectite granules display good biocompatibility and biosecurity. A number of rats from each group $(\mathrm{n}=8)$ were sacrificed on day 14 after treatment. H\&E staining results indicated that numerous inflammatory cells were present in the wound tissues of the starch and blank control groups (Fig. 2A and B). In addition, epithelial regeneration was incomplete in the starch and blank control groups. Neovascularization was indistinctive and fibroblasts were loosely distributed with reduced proliferation, which indicated that the healing process was slow. Compared with the starch and blank control groups, the smectite group displayed a well-formed epidermal layer with a 

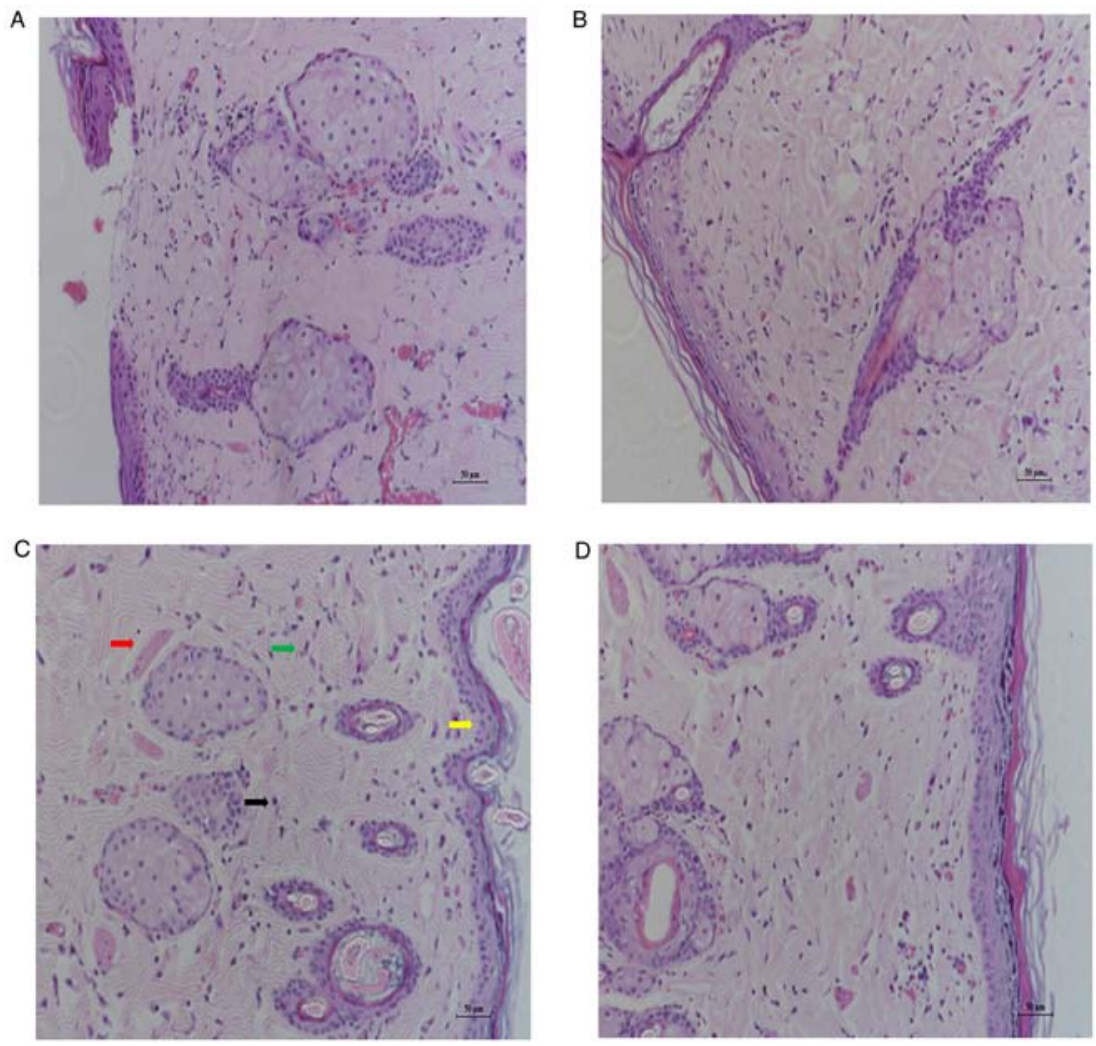

Figure 2. Hematoxylin and eosin staining of wound tissues in blank control, starch, smectite and normal skin groups. The red arrow indicates neovascularization, the green arrow indicates fibroblasts, the yellow arrow indicates the epidermal layer and the black arrow indicates inflammatory cells, Magnification, x200. Scale bar, $50 \mu \mathrm{m}$. (A) Blank control group. (B) Starch group. (C) Smectite group. (D) Normal skin group.

Table II Wound closure rate in the blank control, starch and smectite groups.

\begin{tabular}{lc}
\hline $\begin{array}{l}\text { Smectite } \\
\text { concentration }\left(\mathrm{mg} / \mathrm{mm}^{2}\right)\end{array}$ & $\begin{array}{c}\text { Wound healing } \\
\text { time }(\text { day }), \text { mean } \pm \mathrm{SD}\end{array}$ \\
\hline 0.1 & $16.17 \pm 1.47$ \\
0.5 & $14.00 \pm 0.89^{\mathrm{a}}$ \\
1.0 & $14.17 \pm 0.75^{\mathrm{a}}$ \\
\hline
\end{tabular}

${ }^{\mathrm{a}} \mathrm{P}<0.05$ vs. $0.1 \mathrm{mg} / \mathrm{mm}^{2}$.

remarkable degree of neovascularization, increased fibroblast counts and less inflammatory cells (Fig. 2C). In addition, the boundary layer between the dermis and epidermis was clear and a number of skin appendages were observed in the smectite group (Fig. 2C). The H\&E staining results of the smectite group were closest to the results of the normal group (Fig. 2D). Therefore, the results indicated that wound healing was more efficient in rats treated with mineral smectite granules.

Smectite granules increase collagen fiber content. Collagen fibers were stained reddish-yellow with picrosirius red (Fig. 3A). T=Three randomly selected fields of view were observed and the mean percentage of the marked area that was stained reddish-yellow was calculated using ImageJ software. The smectite group $(77.57 \pm 2.68 \%)$ displayed significant increased collagen distribution compared with blank control and starch groups $(60.84 \pm 2.42$ and $67.35 \pm 3.05 \%$, respectively), and most closely resembled the collagen content of normal

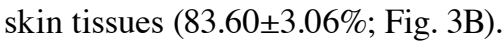

Similar results were obtained for hydroxyproline levels. The hydroxyproline content of the smectite group $(6.51 \pm 0.10 \mu \mathrm{m} / \mathrm{mg})$ was significantly higher compared with the starch $(4.54 \pm 0.14 \mu \mathrm{m} / \mathrm{mg})$ and blank control $(3.46 \pm 0.16 \mu \mathrm{m} / \mathrm{mg})$ groups (Fig. 3C). The hydroxyproline content of the smectite group most closely resembled the hydroxyproline content of normal skin tissues (7.14 $\pm 0.08 \mu \mathrm{m} / \mathrm{mg}$; Fig. 3C). The results indicated that mineral smectite granules promoted collagen synthesis.

Smectite granules induce angiogenesis. CD31 is one of the most prominent angiogenic markers (18). New blood vessels were immunostained brown (Fig. 4A). Three randomly selected fields of view were observed and neovascularization was quantified using ImageJ software. The number of blood vessels in each field of view was counted and the mean was calculated. The results indicated that the number of blood vessels in the smectite group $(49.63 \pm 2.62)$ was significantly higher compared with blank control and starch groups $(23.00 \pm 2.27$ and $33.63 \pm 2.45$, respectively; Fig. 4B). In addition, the number of blood vessels in the smectite group most closely resembled the number of blood vessels in normal skin tissues (64.88 \pm 3.27 ; Fig. 4B).

\section{Discussion}

Wounds affect patient quality of life, requiring extended hospitalization and leading to significant healthcare expenses. 
A

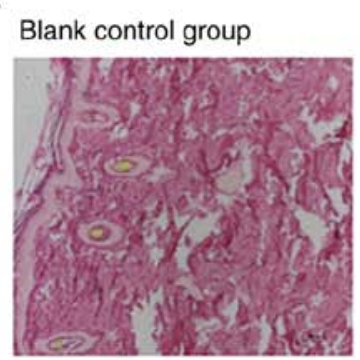

Smectite group

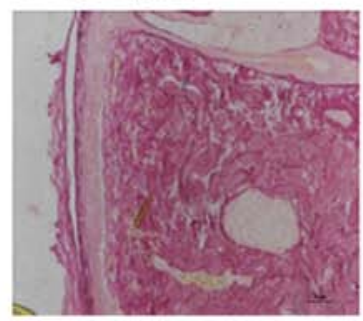

Starch group

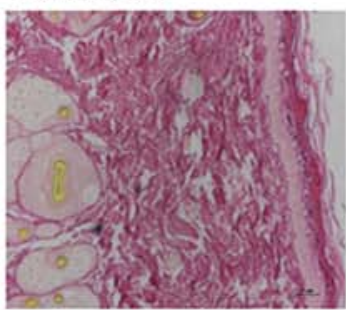

Normal skin

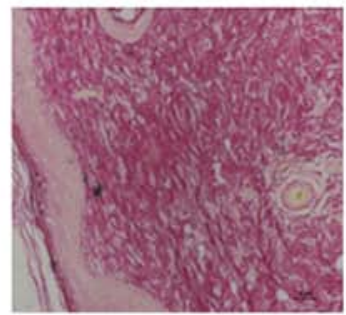

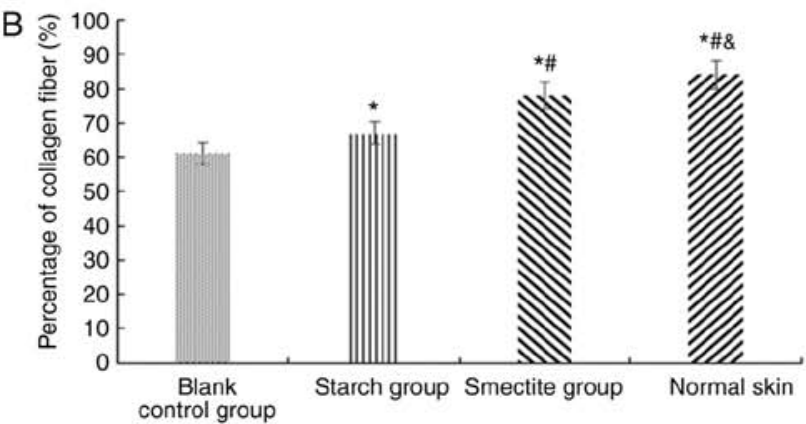

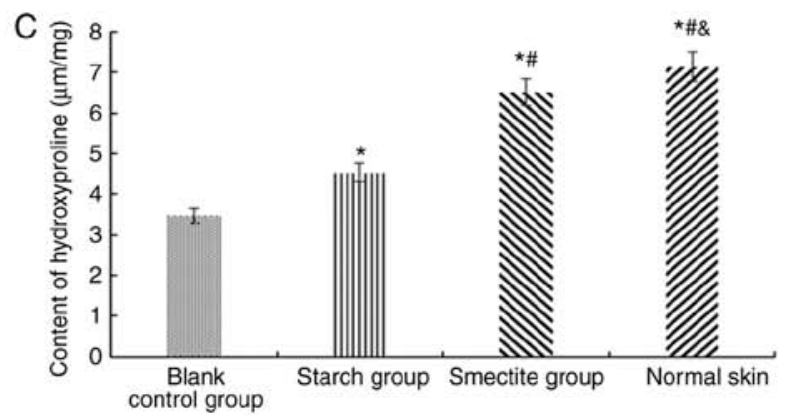

Figure 3. Smectite granules increase the percentage of collagen fibers and hydroxyproline content. (A) Picrosirius red staining of wound tissues in blank control, starch, smectite and normal skin groups. Magnification, x200. Scale bar, $50 \mu \mathrm{m}$. (B) The percentage of (B) collagen fibers and (C) hydroxyproline content in blank control, starch, smectite and normal skin groups. ${ }^{*} \mathrm{P}<0.05$ vs. blank control. ${ }^{~} \mathrm{P}<0.05$ vs. starch. ${ }^{\text {\& }} \mathrm{P}<0.05$ vs. smectite.

A Blank control group

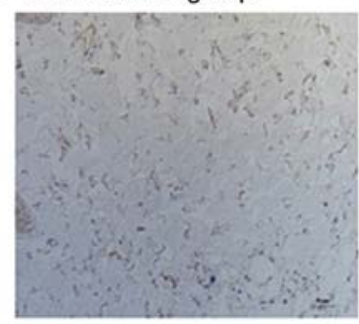

Smectite group

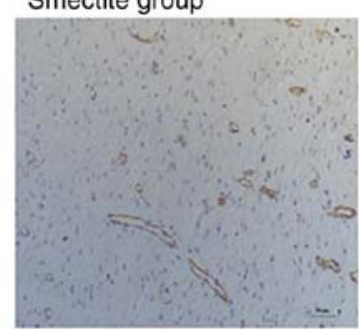

\section{Starch group}

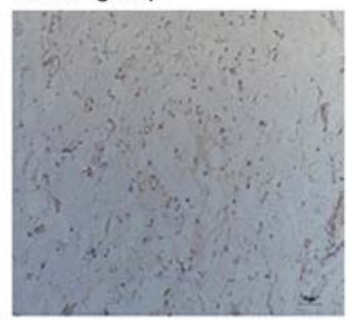

Normal skin

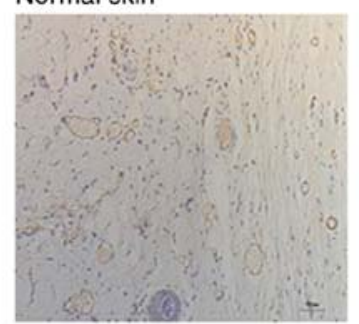

B

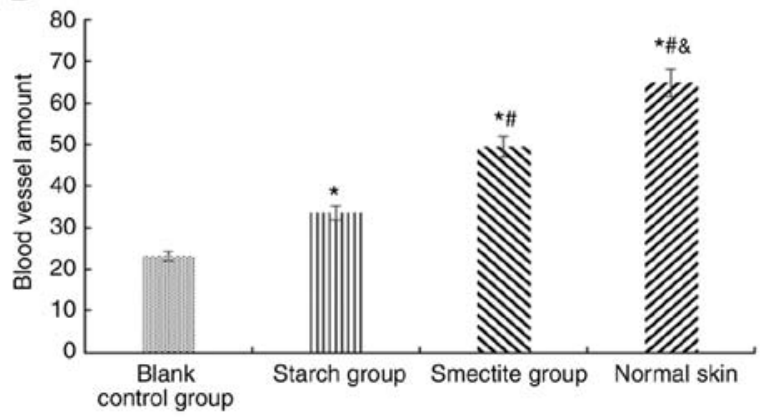

Figure 4. Smectite granules induce angiogenesis. (A) Immunohistochemical staining with anti-CD31 antibodies to identify new blood vessels in the blank control, starch, smectite and normal skin groups. Magnification, x200. Scale bar, $50 \mu \mathrm{m}$. (B) The number of blood vessels in blank control, starch, smectite and normal skin groups. ${ }^{*} \mathrm{P}<0.05$ vs. blank control. ${ }^{*} \mathrm{P}<0.05$ vs. starch. ${ }^{\&} \mathrm{P}<0.05$ vs. smectite.

Therefore, curing the wound rapidly with functional results is the aim of clinical treatment; however, to the best of our knowledge, studies investigating the effect of topical agents on wound healing are limited (19). Fibroblast growth factor is the most effective therapeutic for wound healing, but its application is limited due to its high cost $(20,21)$. Natural products serve as an important type of therapeutic agents. A number of studies have evaluated the effects of plant extracts on wound healing, such as Opuntia flower extracts $(5,22)$. However, a key limitation of plant extracts is the extraction process is complicated, leading to uncertain results. In addition, bleeding and infection often make wound closure difficult. Smectite has been used to treat diarrhea (23), however, it also displays hemostatic and antibacterial properties that may be beneficial for wound healing $(8,24)$. Therefore, the present study evaluated the efficacy and safety of smectite on cutaneous injury.

Wound healing is a complex physiological process that involves multiple cell types and tissues (1). The injured skin is vulnerable to microbial infection that can interfere with the healing process (25). Granulation tissue serves important roles in tissue repair, such as recovering the wound surface, fighting infection and encasing foreign bodies (26). Granulation tissue is made up of new capillaries and fibroblasts, as well as infiltrating inflammatory cells. Subsequently, the number of 
inflammatory cells decreases, and a large number of collagen fibers are produced by fibroblasts (27). Collagen has a key function in wound healing and is the main component of extracellular matrix, which serves a vital role in cell differentiation, tissue repair and organ nourishing (28). Additionally, collagen can also activate macrophage phagocytosis, enhance the immune function and decrease the infectious rate of wounds (29). Sasaki et al (30) reported that collagen deposition was accelerated and the density of collagen fibers was increased upon application of $\mathrm{Mg}$-smectite in a rat cutaneous wound model. In the present study, the collagen was mainly located in the site of application of mineral smectite granules. Therefore, it was hypothesized that the collagen localization may be changed according to the distribution of mineral smectite granules. Hydroxyproline is a degradation product of collagen, which is an essential amino acid for cell repair, providing abundant nourishment and promoting wound healing (31). In the present study, the wound healing effect of smectite granules was evaluated using a rat wound model. The number of blood vessels, collagen fiber content and hydroxyproline content of the smectite group were significantly higher compared with the blank control and starch groups, which indicated that smectite may promote rapid wound healing. During the experimental period, assessment rat weight suggested that there were no significant differences among the groups and no side effects were observed, which indicated that smectite was safe and biocompatible in rats. Furthermore, the H\&E staining results indicated that the smectite group presented with fewer inflammatory cells compared with the blank control and starch groups, which suggested that smectite granules could form a barrier against microbial contamination. The results from previous antibacterial activity assays indicated that smectite could prevent the Gram-positive bacterial infection, which are pathogens that are usually involved in skin infections $(32,33)$. Starches were used as the positive control group due to its low cost, wide availability, biocompatibility and wound healing properties (34). In addition, starches display similar physical characteristics to smectite granules (35). Compared with the blank control group, the wound in the starch group recovered more quickly, which suggested that starch may also promote wound healing, as reported in previous studies (36).

The process of wound healing is not only associated with cell regrowth, but also with dissolving and absorbing necrotic tissues (27). The present study did not investigate whether smectite granules influenced the dissolving or absorbing processes of necrotic tissue; therefore, the molecular mechanism underlying smectite-induced wound healing requires further investigation. The present study had a number of limitations. Firstly, the present study used an animal wound model, but as rat skin differs from human skin, the results of the present study need to be verified in human skin. Secondly, only one prominent angiogenic marker (CD31) was used in the present study. More valid markers are needed to confirm the present findings, such as EGF and TGF- $\beta 1$. Thirdly, some studies have indicated that smectite granules can lead to distal thrombosis in a vascular injury wound model $(11,37)$, but the present study did not investigate the long-term safety of smectite granules.

In conclusion, the topical application of mineral smectite granules increased the percentage of wound contraction, inhibited infection, accelerated re-epithelialization and stimulated neovascularization and maturation of the extracellular matrix. The results provided a potential explanation for how smectite granules may enhance the wound healing process. The present study suggested that mineral smectite granules displayed wound healing potential; however, further studies are required to improve the experimental scheme and identify the underlying molecular mechanisms.

\section{Acknowledgements}

Not applicable.

\section{Funding}

No funding was received.

\section{Availability of data and materials}

The datasets used and/or analyzed during the present study are available from the corresponding author on reasonable request.

\section{Authors' contributions}

JW and MW designed the study and drafted the manuscript. LZ and LL acquired and analyzed the data. XW and ZF constructed the animal model and revised the manuscript. All authors read and approved the final manuscript.

\section{Ethics approval and consent to participate}

This animal experimental was performed according to the Guidelines for Animal Experimentation of Nanjing Medical University and approved by the Animal Ethical and Welfare Committee of Nanjing Medical University, China (IACUC approval no. 1601136).

\section{Patient consent for publication}

Not applicable.

\section{Competing interests}

The authors declare that they have no competing interests.

\section{References}

1. Han G and Ceilley R: Chronic wound healing: A review of current management and treatments. Adv Ther 34: 599-610, 2017.

2. Yamakawa S and Hayashida K: Advances in surgical applications of growth factors for wound healing. Burns Trauma 7: 10, 2019.

3. Schaffer CJ and Nanney LB: Cell biology of wound healing. Int Rev Cytol 169: 151-181, 1996.

4. Fu X, Shen Z, Chen Y, Xie J, Guo Z, Zhang M and Sheng Z: Randomised placebo-controlled trial of use of topical recombinant bovine basic fibroblast growth factor for second-degree burns. Lancet 352: 1661-1664, 1998.

5. Ammar I, Bardaa S, Mzid M, Sahnoun Z, Rebaii T, Attia H and Ennouri M: Antioxidant, antibacterial and in vivo dermal wound healing effects of Opuntia flower extracts. Int J Biol Macromol 81: 483-490, 2015.

6. Fikru A,Makonnen E, Eguale T, Debella A and Abie Mekonnen G: Evaluation of in vivo wound healing activity of methanol extract of Achyranthes aspera L. J Ethnopharmacol 143: 469-474, 2012. 
7. Pérez-Gaxiola G, Cuello-García CA,Florez ID and Pérez-Pico VM: Smectite for acute infectious diarrhoea in children. Cochrane Database Syst Rev 4: CD011526, 2018.

8. Gerlach T, Grayson JK, Pichakron KO, Sena MJ, DeMartini SD, Clark BZ, Estep JS and Zierold D: Preliminary study of the effects of smectite granules (WoundStat) on vascular repair and wound healing in a swine survival model. J Trauma 69: 1203-1209, 2010

9. Hou FQ, Wang Y, LI J, Wang GQ and Liu Y: Management of acute diarrhea in adults in China: A cross-sectional survey. BMC Public Health 13: 41, 2013.

10. Pourshahrestani S, Zeimaran E, Djordjevic I, Kadri NA and Towler MR: Inorganic hemostats: The state-of-the-art and recent advances. Mater Sci Eng C Mater Biol Appl 58: 1255-1268, 2016.

11. Kheirabadi BS, Mace JE, Terrazas IB, Fedyk CG, Estep JS, Dubick MA and Blackbourne LH: Safety evaluation of new hemostatic agents, smectite granules, and kaolin-coated gauze in a vascular injury wound model in swine. J Trauma 68: 269-278, 2010.

12. Wang J, Zhao L, Liu W, He K, Wang M and Fan Z: Treatment outcomes of mineral smectite granules in the hemorrhage rat model. Jinagsu Med J 44: 484-487, 2018 (In Chinese)

13. Guo $S$ and Dipietro LA: Factors affecting wound healing. J Dent Res 89: 219-229, 2010.

14. Jaykamn, Yadav $\mathrm{P}$ and Kantharia ND: Ethics in animal experiments. Indian J Med Ethics 9: 70-71, 2012.

15. Rittié L: Method for picrosirius red-polarization detection of collagen fibers in tissue sections. Methods Mol Biol 1627: 395-407, 2017.

16. Colgrave ML, Allingham PG and Jones A: Hydroxyproline quantification for the estimation of collagen in tissue using multiple reaction monitoring mass spectrometry. J Chromatogr A 1212: $150-153,2008$

17. Márquez WH, Gómez-Hoyos J, Woodcock S, Arias LF, Sampson TG and Gallo JA: The regional microvascular density of the gluteus medius tendon determined by immunohistochemistry with CD31 staining: A cadaveric study. Hip Int 25: 168-171, 2015.

18. de Almeida CM, de Jesus SF, Poswar Fde O, Gomes ES, Fraga CA, Farias LC, Santos SH, Feltenberger JD, de Paula AM and Guimarães AL: Increasing demonstration of angiogenic markers in skin neoplastic lesions. Pathol Res Pract 212: 101-105, 2016.

19. Rizzi SC, Upton Z, Bott K and Dargaville TR: Recent advances in dermal wound healing: Biomedical device approaches. Expert Rev Med Devices 7: 143-154, 2010.

20. Huang W, Shao M, Liu H, Chen J, Hu J, Zhu L, Liu F, Wang D, Zou Y, Xiong Y and Wang X: Fibroblast growth factor 21 enhances angiogenesis and wound healing of human brain microvascular endothelial cells by activating PPAR $\gamma$. J Pharmacol Sci 140: 120-127, 2019.

21. Maddaluno L, Urwyler C and Werner S: Fibroblast growth factors: Key players in regeneration and tissue repair. Development 144: 4047-4060, 2017.

22. Tsala DE, Habtemariam S, Simplice FH, Martin Thierry BN, Abraham JA and Theophile D: Topically applied Tetrapleura tetraptera stem-bark extract promotes healing of excision and incision wounds in rats. J Intercult Ethnopharmacol 3: 63-67, 2014.
23. Donauerová A, Bujdák J, Smolinská M and Bujdáková $H$ : Photophysical and antibacterial properties of complex systems based on smectite, a cationic surfactant and methylene blue. J Photochem Photobiol B 151: 135-141, 2015.

24. Gurtner GC, Werner S, Barrandon Y and Longaker MT: Wound repair and regeneration. Nature 453: 314-321, 2008.

25. Long KB, Burgwin CM, Huneke R, Artlett CM and Blankenhorn EP: Tight skin 2 mice exhibit delayed wound healing caused by increased elastic fibers in fibrotic skin. Adv Wound Care (New Rochelle) 3: 573-581, 2014.

26. Reinke JM and Sorg H: Wound repair and regeneration. Eur Surg Res 49: 35-43, 2012.

27. Martin P and Nunan R: Cellular and molecular mechanisms of repair in acute and chronic wound healing. Br J Dermatol 173: 370-378, 2015

28. Kallis PJ and Friedman AJ: Collagen powder in wound healing. J Drugs Dermatol 17: 403-408, 2018.

29. Chattopadhyay S and Raines RT: Review collagen-based biomaterials for wound healing. Biopolymers 101: 821-833, 2014.

30. Sasaki Y, Sathi GA and Yamamoto O: Wound healing effect of bioactive ion released from Mg-smectite. Mater Sci Eng C Mater Biol Appl 77: 52-57, 2017.

31. El-Mesallamy HO, Diab MR, Hamdy NM and Dardir SM: Cell-based regenerative strategies for treatment of diabetic skin wounds, a comparative study between human umbilical cord blood-mononuclear cells and calves' blood haemodialysate. PLoS One 9: e89853, 2014.

32. Li S, Guo Y, Zhao C, Chen H, Hu B, Chu Y, Zhang Z, Hu Y, Liu Z, Du Y, et al: In vitro activities of tedizolid compared with other antibiotics against Gram-positive pathogens associated with hospital-acquired pneumonia, skin and soft tissue infection and bloodstream infection collected from 26 hospitals in China. J Med Microbiol 65: 1215-1224, 2016.

33. Huang DB, Magnet S, De Angelis S, Holland TL, File TM Jr, Dryden M, Corey GR, Torres A and Wilcox MH: Surveillance of iclaprim activity: In vitro susceptibility of Gram-positive skin infection pathogens collected from 2015 to 2016 from North America and Europe. Diagn Microbiol Infect Dis 93: 154-158, 2019.

34. Waghmare VS, Wadke PR, Dyawanapelly S, Deshpande A, Jain R and Dandekar P: Starch based nanofibrous scaffolds for wound healing applications. Bioact Mater 3: 255-266, 2017.

35. Baghaie S, Khorasani MT, Zarrabi A and Moshtaghian J: Wound healing properties of PVA/starch/chitosan hydrogel membranes with nano zinc oxide as antibacterial wound dressing material. J Biomater Sci Polym Ed 28: 2220-2241, 2017.

36. Amal B, Veena B, Jayachandran VP and Shilpa J: Preparation and characterisation of Punica granatum pericarp aqueous extract loaded chitosan-collagen-starch membrane: Role in wound healing process. J Mater Sci Mater Med 26: 181, 2015.

37. Kheirabadi BS, Edens JW, Terrazas IB, Estep JS, Klemcke HG, Dubick MA and Holcomb JB: Comparison of new hemostatic granules/powders with currently deployed hemostatic products in a lethal model of extremity arterial hemorrhage in swine. J Trauma 66: 316-326, 2009.

This work is licensed under a Creative Commons Attribution-NonCommercial-NoDerivatives 4.0 International (CC BY-NC-ND 4.0) License. 